\title{
Preconditions of Analysis: an Appraisal of Interconnected Rational Dynamics
}

\author{
Saeed Shoja Shaft
}

University of Social Welfare and Rehabilitation Sciences (USWR), Razi Psychiatric Hospital, Tehran - Iran

Corresponding Author: Saeed Shoja Shafti, University of Social Welfare and Rehabilitation Sciences (USWR), Razi Psychiatric Hospital, Tehran - Iran .

Received Date: February 17, 2020; Accepted Date: April 20, 2020; Published Date; May 11, 2020.

Citation: Saeed Shoja Shafti, Preconditions of Analysis: An Appraisal of Interconnected Rational Dynamics, J. Psychology and Mental Health Care.4 (3) Doi: 10.31579/2637-8892/078

Copyright: (9) 2020. Saeed Shoja Shafti, This is an open-access article distributed under the terms of the Creative Commons Attribution License, which permits unrestricted use, distribution, and reproduction in any medium, provided the original author and source are credited.

\begin{abstract}
Summery:
Sluggish or lumpy progression of psychoanalysis or other insight-oriented psychotherapies, in opposite to non-analytical techniques, in unindustrialized societies or traditional nations, during the first decades of present century, in spite of availability of main references or resources, may suggest an exact rational or cognitive foundation, other than well-known socioeconomic explanations. Such sluggishness is worthy of analysis, because, chronologically, the similar course was not so slow in developed societies throughout the comparable period in the last century. Hence, disregard or in addition to evolutionary, sociobiological or cultural-historical rationalizations, some eccentricity in thought, among traditional persons in evolving societies, as likely equivalent to conservative persons in industrialized societies, may account for such kind of deficiency or evading, which hinders, as a general rule, systematic practice of psychoanalytic techniques in traditional cultures. In present article, different physiognomies and mechanisms of this topic, including some of the interconnected modules or philosophies, like 'Empiricism', 'Positivism', 'Biologism', 'Individualism', 'Liberalism', 'Conservatism' and 'Analytical Thinking', which act willingly or incidentally, deliberately or impulsively, as cultural arbitrators in psychosocial interferences, will be talked over briefly.
\end{abstract}

Keywords: rational dynamics: psychoanalysis; psychotherapies; non-analytical techniques

\section{Analysis as a never-ending and all-embracing practice:}

As is known, psychoanalysis involves analysis of resistance, analysis of transference, analysis of counter-transference, analysis of dream (interpretation of dreams), analysis of slips, analysis of free association and so on (1-5). So, analysis, as the main tool for probing unconscious realm, is the backbone of psychoanalysis, which as well should be internalized in the patient, as a management tool for self-analysis in future and after termination of therapeutic sessions along with analyst (6). Principally, the major difference between psychoanalysis and other psychotherapeutic techniques is around induction or revelation of insight by means of thorough and deep analysis of unconscious byproducts by the first method, and counseling, supporting, or reorganizing of consciousness or pre-consciousness by the other techniques. Therefore, analysis and analytical thinking, while is the most important tool in the first technique, is not crucial in the other ones. Accordingly, why, in opposite to non-insight-oriented methods, progression of methodical psychoanalysis is so sluggish or uneven in developing societies during the first decades of present century, while, chronologically, it was not so in developed societies during the comparable period in last century. After publishing 'studies in hysteria' by Freud and Breuer in 1985 (7) and during a few decades, psychoanalysis had occupied a great position in behavioral science as a systematic therapeutic method with its specific theories and techniques. At the same time, while a number of psychoanalytic writings were available in various developing countries, which could instigate, for example, extra curiosity or probing by scholars of those societies, in effect, no significant efforts were traceable, whether tentatively or practically, up to recent decades (8). But even at the moment, in spite of obtainability of a lot of valued translations and texts, professional inclinations is clearly far from clinical and applied psychoanalysis $(9,10$ and 11). Why the state of affairs is so? In the midst of a variety of socio-cultural explanations, which have been described elsewhere $(12,13)$, cognitive origins, also, need to be addressed more precisely than before. According to data, cognitive operations are not always in harmony with intellectual abilities, and different preferences, whether genetically-based or environmental-based, may depend on various temperaments, which operate intuitively. Therefore, professional inclinations in evolving cultures, with noticeable traditional indexes, toward non-analytical psychotherapeutic methods may have cognitive justifications, independent from habitual customs or values. If traditionalism in developing societies is roughly comparable to conservatism in developed societies (14), then a comparative review becomes possible. In this regard and first of all, some of the interconnected elements or concepts, like 'Empiricism', 'Positivism', 'Biologism', 'Individualism', 'Liberalism', 'Conservatism' and 'Analytical Thinking', which act directly or indirectly, consciously or unconsciously, as mediators in psychosocial interventions, must be pointed out to depict a general outline with respect to the present debate.

\section{Empiricism:}

Empiricism, often used by natural scientists, says that "knowledge is based on experience" and that "knowledge is tentative and probabilistic, subject to continued revision and falsification". Empirical research, including experiments and validated measurement tools, guides the scientific method. In philosophy, empiricism is a theory that states that knowledge comes only or primarily from sensory experience. So, empiricism emphasizes the role of empirical evidence in the formation of ideas, rather than innate ideas or traditions and empiricism in the philosophy of science emphasizes evidence, especially as discovered in experiments. It is a fundamental part of the scientific method that all 
hypotheses and theories must be tested against observations of the natural world rather than resting solely on a priori reasoning, intuition, or revelation (15).

\section{Positivism:}

While comparable with Experientialism, which asserts that knowledge begins and ends with experience itself, Positivism is a philosophical theory stating that certain ("positive") knowledge is based on natural phenomena and their properties and relations. Thus, information derived from sensory experience, interpreted through reason and logic, forms the exclusive source of all certain knowledge. Verified data (positive facts) received from the senses are known as empirical evidence; thus positivism is based on empiricism. Positivism also holds that society, like the physical world, operates according to general laws. Introspective and intuitive knowledge is rejected, as are metaphysics and theology because metaphysical and theological claims cannot be verified by sense experience. Positivism asserts that all authentic knowledge allows verification and that all authentic knowledge assumes that the only valid knowledge is scientific. Modern positivists generally eschew metaphysical concerns in favor of methodological debates concerning clarity, replicability, reliability and validity. While avoiding extreme expressions of logical positivism or Scientism (the dogmatic endorsement of scientific methodology and the reduction of all knowledge to only that which is measured or confirmatory), the key features of positivism are: A focus on science as a product; A concern with demonstrating the logical structure and coherence of statements, some of which at least should be testable, as well; that is, amenable to being verified, confirmed, or shown to be false by the empirical observation of reality. Also, The opinion that science is cumulative and transcultural, and rests as well on specific results that are dissociated from the personality and social position of the investigator. Moreover, accepting that science sometimes incorporates new ideas that are discontinuous from old ones and science is nature and nature is science; and out of this duality, all theories and postulates are created, interpreted, evolve, and are applied (16).

\section{Biologism:}

As is known, a psychotherapist should generally base his or her professional perspective on recognized 'Bio-Pycho-Social' model of philosophy; by taking into account various biological, psychological and social dynamics, which together shape behavior and personality of human being. Psychoanalysis, though considering the aforesaid issues in addition to spiritual aspects, demands a wholesome biological attitude for detection of truths and attainment of insight in patients. Without that, there will be no clear-cut boundary between psychoanalysis, as the basic method of insight-oriented psychotherapies, and other techniques of psychotherapy, which do not care or rely specifically on patient's insight. So, 'Biologism', as the use of biological explanations in the analysis of social situations (17) seems to be a mandatory attitude. While maybe it is not obligatory for an analyst to take the most reductive version of the 'New Biologism', which see life as a programmed process and culture as its interface, tendency to make use of biological determinism and concepts from biology to explain behavior and psychological phenomena and to avoid purely psychological concepts and principles for such explanation, is a prerequisite for such kind of therapeutic tactic (18). Without such position, which itself depends on historical, developmental, cultural, educational, and outlook of analyst, and cannot be brought about in a while, discovery of events, pains, happenings, and ultimate achievement of insight, may easily bump into trouble, stalemate, distortion and , in conclusion, failure.

\section{Individualism:}

Individualism is the moral stance, political philosophy, ideology, or social outlook that emphasizes the moral worth of the individual. Individualists promote the exercise of one's goals and desires and so value independence and self-reliance and advocate that interests of the individual should achieve precedence over the state or a social group, while opposing external interference upon one's own interests by society or institutions such as the government. Individualism is often defined in contrast to totalitarianism, collectivism, and more corporate social forms. Individualism makes the individual its focus and so starts with the fundamental premise that the human individual is of primary importance in the struggle for liberation. Individualism thus involves the right of the individual to freedom and self-realization. Individualism is thus also associated with artistic and bohemian interests and lifestyles where there is a tendency towards self-creation and experimentation as opposed to tradition or popular mass opinions and behaviors, as with humanist philosophical positions and ethics. The individualist does not follow one particular philosophy, rather creates an amalgamation of elements of many, based on personal interests in particular aspects that he/she finds of use. Independent thinking and opinion is a common trait of an individualist. Societies and groups can differ in the extent to which they are based upon predominantly "self-regarding" (individualistic, and/or self-interested) behaviors, rather than "other-regarding" (grouporiented, and group, or society-minded) behaviors. Individualism is often contrasted either with totalitarianism or with collectivism, but in fact, there is a spectrum of behaviors at the societal level ranging from highly individualistic societies through mixed societies to collectivist (19).

\section{Liberalism:}

A liberal attitude toward anything means more tolerance for change. There are many meanings for liberal, but they mostly have to do with freedom and openness to change. Liberalism is the belief in the importance of individual freedom. This belief is widely accepted in developed societies and was recognized as an important value by many Western philosophers throughout history. Liberalism comes in many forms. The essence of liberalism is toleration of different beliefs and of different ideas as to what constitutes a good life. Liberalism-both as a political current and an intellectual tradition-is mostly a modern phenomenon that started in the $17^{\text {th }}$ century, although some liberal philosophical ideas had precursors in classical antiquity. Besides liberty, liberals have developed several other principles important to the construction of their philosophical structure, such as equality, pluralism and toleration. In maintaining that people are naturally equal, liberals assume that they all possess the same right to liberty. In other words, no one is inherently entitled to enjoy the benefits of liberal society more than anyone else and all people are equal subjects before the law (20).

\section{Conservatism:}

Conservatism is a political and social philosophy promoting traditional social institutions in the context of culture and civilization. The central tenets of conservatism include tradition, human imperfection, organic society, hierarchy, authority, and property rights. Conservatives seek to preserve a range of institutions with the aim of emphasizing social stability and continuity. It usually opposes modernism and seeks a return to the way things were. There is no single set of policies regarded as conservative because the meaning of conservatism depends on what is considered traditional in a given place and time. Thus conservatives from different parts of the world - each upholding their respective traditionsmay disagree on a wide range of issues. Cultural conservatives hold fast to traditional ways of thinking even in the face of monumental change. They believe strongly in traditional values and traditional politics and often have an urgent sense of nationalism. In most democracies, political conservatism seeks to uphold traditional family structures and social 
values. In some cases, conservative values are grounded in religious beliefs, and conservatives seek to increase the role of religion in public life. Following the Second World War, psychologists conducted research into the different motives and tendencies that account for ideological differences between left and right. A meta-analysis of research literature found that many factors, such as intolerance of ambiguity and need for cognitive closure, contribute to the degree of one's political conservatism. A study by Kathleen Maclay stated these traits "might be associated with such generally valued characteristics as personal commitment and unwavering loyalty". The research also suggested that while most people are resistant to change, liberals are more tolerant of it (21).

\section{Analytical thinking:}

Analytical thinking is a powerful thinking tool for understanding the parts of situation and can be defined as the ability to scrutinize and break down facts and thoughts into their strengths and weaknesses, or developing the capacity to think in a thoughtful, discerning way, to solve problems, analyze data, and recall and use information. While analytical thinking enables us to understand the parts of the situation and breaks things down into their component parts and identifying differences, synthetical thinking enables us to understand how they work together and finds the pattern across those component parts and finding similarities. We need both analysis and synthesis. Each is of only limited value without the other in a systemic world. Systemic thinking is nothing more than a combination of analytical thinking and synthetical thinking. Systemic thinking, as well, is a simple thinking technique for gaining systemic insights into complex situations and problems. Systemic thinking enables us to deal with the elements of a situation in concert rather than in isolation. Its power lies in its simplicity and effectiveness. It offers the potential to find system focus in any situation. Systemic thinking is the reverse of analytical thinking. Analytical thinking breaks things apart in stages- systemic thinking group's things together in stages. Synthesis needs analysis- how can you find the similarities across different things, if you have not listed the different things first? Analysis needs synthesisunderstanding how things behave in isolation is pointless. Moreover, analytical thinking is a component of critical thinking. The critical thinking is the ability to analyze facts, generate and organize ideas, defend opinions, make comparisons, draw inferences, evaluate arguments and solve problems. It is intellectually disciplined process of actively and skillfully conceptualizing, applying, analyzing, synthesizing, and/or evaluating information gathered from, or generated by observation, experience, reflection, reasoning, or communication, as a guide to belief and action. It involves analytical thinking for the purpose of evaluating what is ready. Critical thinking allows us to listen to our emotions, without being controlled by them. Finally, creative thinking is relating/creating of things or ideas which were previously unrelated. Analytical thinking assists creativity. Analytical thinking is logical and leads to unique or few answers, which can be implemented. Creative thinking requires imagination, and leads to many possible answers or ideas. While the two sorts of thinking are different, they are linked because one sort complements the other. Analytical thinking is convergent, narrowing down to unique answers or a small number of ideas which can be further analyzed and implemented. Creative thinking is divergent, starting from the description of the problem and diverging to give many ideas for solving it, or possible answer to it. In effect, analytical thinking produces solutions and solution can be selected (22).

\section{Discussion:}

Biology and political orientation is a concept based on a number of studies that have found that biology can be linked with political orientation. This means that biology is a possible factor in political orientation. Recent research points at substantial differences in the cognitive styles of liberals and conservatives on psychological measures (23). For example, conservatives respond to threatening situations with more aggression than do liberals. Similarly, conservatives are more sensitive to threatening facial expressions. According to some scholars, political orientation is associated with psychological processes for managing fear and uncertainty. A neuroimaging study, found a correlation between differences in political views and differences in brain structures in a convenience sample of students. Students who reported more conservative political views tended to have larger amygdalae, a structure in the temporal lobes that performs a primary role in the processing and memory of emotions (24). In addition, they found clusters in which gray matter volume was significantly associated with conservatism in the left insula and the right entrohinal cortex. There is evidence that conservatives are more sensitive to disgust and the insula is involved in the feeling of disgust. On the other hand, more liberal students tended to have a larger volume of grey matter in the anterior cingulate cortex, a structure of the brain associated with monitoring uncertainty and handling conflicting information (24). It is consistent with previous research suggesting that individuals with a larger anterior cingulate cortex have a higher capacity to tolerate uncertainty and conflicts, allowing them to accept more liberal views (24). According to another examination, liberals were significantly more likely than conservatives to show activity in the brain circuits that deal with conflicts during the experiment, and this correlated with their greater accuracy in the test (25). Also, in an fMRI study, three different patterns of brain activation were found to correlate with individualism, conservatism, and radicalism. In addition, another study has identified several genes potentially connected with political ideology. Moreover, conservative persons had greater skin conductance response, indicating greater sympathetic nervous system response, to threatening images than liberals in one study. There was no difference for positive or neutral images. Holding conservative views was also associated with a stronger startle reflex as measured by strength of eye-blink in response to unexpected noise. A study of subjects' reported level of disgust linked to various scenarios showed that people who scored highly on the 'disgust sensitivity scale' held more politically conservative views (25). Also, there are new perspectives like, Genopolitics [ the study of the genetic basis of political behavior and attitudes, which combines behavior genetics, psychology, and political science and closely related to the emerging field of political physiology (the study of bio-physical correlates of political attitudes and behavior)] (26), Neuro-politics [ which investigates the interplay between the brain and politics and combines work from a variety of scientific fields including neuroscience, political science, psychology, behavioral genetics, primatology, and ethology] (27), and Biological determinism [ also known as genetic determinism, as the belief that human behavior is controlled by an individual's genes or some component of their physiology, generally at the expense of the role of the environment, whether in embryonic development or in learning] (28). Genetic reductionism is a similar concept, but it is distinct from genetic determinism in that the former refers to the level of understanding, while the latter refers to the supposedly causal role of genes (26). In summary, all these perspectives emphasize that state of mind is not independent from tough organic considerations, which in turn is not free from evolutionary or sociobiological (29) conjectures, though, perhaps according to Vygotsky's Cultural-Historical theory (30), it is not static or refractory to working out, too. Likewise, as said by Talhelm et al., while thought styles - whether analytical or holistic - can be changed through training, liberals and conservatives in the same developed society think as if they are from completely different cultures - almost as different as East vs. West (31). Liberals and conservatives categorize and perceive things differently, and while political conservatives are intuitive or holistic thinkers, liberals are more analytical thinkers. Also according to them, while liberals tend to view scenes, explain behavior and categorize objects analytically, the vast majority of people around the world - about 85 
percent - more often think intuitively - what psychologists call holistic thought. Holistic thought more often uses intention and the perception of whole objects or situations, rather than breaking them down into their parts (31). Analytic thinking styles tend to look at the parts of a situation, and how they work together toward the whole. This involves slicing up the world and analyzing objects individually, divorced from context. Studies show that analytical thinkers predominate in Western, educated, industrialized, rich and democratic societies (termed "WEIRD" societies in 2010 by a team of cultural psychologists at the University of British Columbia). But they make up only about 15 percent of the world's population. Intuitive thinking likely is the default style most people are born with, while analytical thinking generally must be learned, usually through training. In summary, liberals tended to be analytic thinkers and the conservatives' holistic thinkers (31). But cultural psychologists further found that political thought was somewhat malleable. They discovered that if they trained holistic thinkers to think analytically, they would subsequently start viewing the world more liberally. Likewise, liberals, if trained to think holistically, would come to form more conservative opinions. According to Talhelm et al., liberals in the West tend to live in urban or suburban areas and often have fairly weak social and community ties, move more often and are less traditionally religious (31). They are more individualistic than conservatives and very unlike most people in Eastern cultures. Conservatives, on the other hand, tend to be more connected to their communities and may live in the same areas throughout their lives, maintaining strong social and familial bonds and commitments, and are more traditionally religious. This puts them more in line with the holistic-thinking majority of the world (30).

\section{Conclusion:}

In line with the above-mentioned suggestions, psychoanalysis depends on, firstly, Analytical thinking, as the ability to scrutinize and break down facts and thoughts into their strengths and weaknesses, and the capacity to think in a thoughtful, discerning way, to solve problems, analyze data, and recall and use information, and, as well, as the initial stage in synthetical, systemic, critical and creative thinking for acquisition or induction of insight. Secondly, it depends on Individualism, as a philosophy, which involves the right of the individual to freedom, selfrealization, self-creation and experimentation; and, lastly, on Liberalism, as belief in the importance of individual freedom and toleration of different beliefs and ideas. Perspectives like Biologism, Empericism and Positivism, as well, are indispensable bases for creation of analytical thinking. Regrettably, all the said components are not the principal style of thinking, philosophy or conviction in traditional or conservative societies. While, liberal thinking, in comparison with conservative thinking, is not a predominant style of philosophy, as well, in technologically advanced civilizations, but the social and political circumstances in developed and democratic societies permit its manifestation and operation more stress-free and comprehensive in comparison with the most unindustrialized and autocratic societies. Technologic advancements and increasing influx of data may modify the upcoming generations' frame of mind and reverse the present situation more constructively in future.

\section{References:}

1. Freud, S. 'Papers on technique'. In: J. Strachey, et al (Eds). The standard edition of the complete psychological works of Sigmund Freud, 24 vols.1912, Vol. 12, London: The Hogart Press. pp. 111-120.

2. Freud. S. 'The Psychopathology of Everyday Life'. In: J. Strachey, et al (Eds) The standard edition of the complete psychological works of Sigmund Freud, 24 vols , 1901,Vol. 6 ,London: The Hogart Press. pp. 6-291.
3. Freud. S. 'The Interpretation of Dreams'. In: J. Strachey, et al (Eds) The standard edition of the complete psychological works of Sigmund Freud, 24 vols , 1900, Vol. 4, London: The Hogart Press. pp. 5-623.

4. Bergmann MS. Termination and Reanalysis. In TEXTBOOK OF PSYCHOANALYSIS: edited by Person ES, Cooper AM, Gabbard GO, Arlington, VA, American Psychiatric Publishing, Inc. (APPI), 2005. p. 244-247.

5. Samberg E, Marcus ER. Process, Resistance, and Interpretation. In TEXTBOOK OF PSYCHOANALYSIS: edited by Person ES, Cooper AM, Gabbard GO, Arlington, VA, American Psychiatric Publishing, Inc. (APPI), 2005 .p. 237239.

6. Colombo D, Abend SM. Psychoanalysis: The Early Years: In TEXTBOOK OF PSYCHOANALYSIS: edited by Person ES, Cooper AM, Gabbard GO, Arlington, VA, American Psychiatric Publishing, Inc. (APPI), 2005. p. 384.

7. Freud.S, Breuer.J. 'Studies on Hysteria.' In: J. Strachey, et al (Eds) The standard edition of the complete psychological works of Sigmund Freud, 24 vols , 1893-1895, Vol. 2, London: The Hogart Press. pp. 2-307.

8. Shoja Shafti S. 'Psychoanalysis in Persia'. American Journal of Psychotherapy. 2005, 59(4): 385-389.

9. Shoja Shafti S. Practicing Psychoanalysis and Psychodynamic Psychotherapies in Developing Societies. American journal of psychotherapy 2016; 70(3): 329-342.

10. Shoja Shafti S. Practice of Psychotherapy by Biological Psychiatrists: An Achievable or Unachievable Expectation. Current Psychiatry Research and Reviews 2016; 12(3): 246252.

11. Shoja Shafti S. Educating Psychological Managements in Present-Day Psychiatry: Is it a Fruitful Struggle. Canadian Journal of Biomed Research and Technology 2019;1(1): 1-7.

12. Shoja Shafti S. Self-understanding: An analytic End-result of Self-absorption. International Journal of Psychoanalysis and Education 2018; 10 (1): 61-72.

13. Shoja Shafti S. Classical Approach as an Operative Outlet to Clinical Psychoanalysis in Evolving Societies. International Journal of Psychoanalysis and Education 2019; 10(1):1-15.

14. Talhelm T, Haidt J, Oishi S, Zhang X, Miao FF, Chen S. Liberals Think More Analytically (More "WEIRD") Than Conservatives. Personality and Social Psychology Bulletin 2010; 14: 1- 18.

15. Macmillan Encyclopedia of Philosophy (1969), "Empiricism", vol. 2, p. 503.

16. Hanfling O. "Logical Positivism". Routledge History of Philosophy. IX. Routledge. 2003. pp. 193-194.

17. https://dictionary.apa.org/biologism

18. Stier M, Schoene-Seifert B, Rüther M, Muders S. The philosophy of psychiatry and biologism. frontires in psychology 2014; 5: 1-3.

19. Brown LS. The Politics of Individualism: Liberalism, Liberal Feminism, and Anarchism. Black Rose Books Ltd. 1993.

20. Conway D. Classical Liberalism: The Unvanquished Ideal. Palgrave Macmillan. 1998.

21. McLean I , McMillan A. "Conservatism", Concise Oxford Dictionary of Politics, Third Edition, Oxford University Press, 2009.

22. Amer A. Analytical Thinking. Center for Advancement of Postgraduate Studies and Research in Engineering Sciences, Cairo University, 2005.

23. Buchen L. "Biology and ideology: The anatomy of politics". Nature. 2012; 490 (7421): 466-468. 
24. R. Kanai. "Political Orientations Are Correlated with Brain Structure in Young Adults". Curr Biol. 2011; 21 (8): 677-80.

25. Jost J, Amodio D. Political ideology as motivated social cognition: Behavioral and neuroscientificevidence . Motivation and Emotion. 2011; 36 (1): 55-64.

26. Charney, Evan; English, William. Genopolitics and the Science of Genetics. American Political Science Review. 2013; 107 (2): 382-395.

27. 27. James F, Schreiber D. Biology, Politics, and the Emerging Science of Human Nature. Science. 2008; 322 (5903): 912-914.
28. Melo-Martín D. "When Is Biology Destiny? Biological Determinism and Social Responsibility". Philosophy of Science. 2003; 70 (5): 1184-91.

29. Wilson E. Sociobiology: The New Synthesis, Cambridge, Harvard University Press, 2000.

30. Vygotsky L S. Mind in Society: The Development of Higher Psychological Processes. Cambridge, MA, Harvard University Press, 1978.

31. Thomas Talhelm, Jonathan Haidt, Shigehiro Oishi, Xuemin Zhang, Felicity F. Miao et al. Liberals Think More Analytically (More "WEIRD") Than Conservatives. Personality and Social Psychology Bulletin 2010; 14: 1- 18.
Ready to submit your research? Choose Auctores and benefit from:

* fast, convenient online submission

* rigorous peer review by experienced research in your field

* rapid publication on acceptance

* authors retain copyrights

* unique DOI for all articles

* immediate, unrestricted online access

At Auctores, research is always in progress.

Learn more www.auctoresonline.org/journals/psychology-and-mentalhealth-care 